\title{
THE DISTRIBUTION OF LEUCOCYTES ON THE COUNTING CHAMBER
}

\author{
BY \\ MARTIN HYNES \\ From the Department of Medicine, University of Cambridge
}

(RECEIVED FOR PUBLICATION, JULY, 1947)

It is almost a statistical truism that the number of cells on each square of a haemocytometer is distributed in a Poisson series, but in fact it is easy to show that the distribution departs considerably from the theoretical expectation. The reason, perhaps, is that the experimental work confirming this theory was done on the old well type of haemocytometer, whereas the Bürker counting chamber is now universally used, and adds new and less predictable variations to random sampling.

My attention was drawn to this point by a statistically controlled series of leucocyte counts on Bürker counting chambers with the Neubauer ruling. I counted, as is usual, the number of cells on four areas of one square millimetre at the corners of a square with a side of three millimetres, and recorded the four sub-totals separately. Over the whole series, the two squares nearest to the filling point of the chamber gave nearly identical totals 3.5 per cent below the mean value for all four squares, and the two further squares similarly gave nearly identical totals 3.5 per cent above the mean value. The difference was statistically highly significant. It seemed worth while to test the extent of this deviation from the theoretical Poisson distribution, and to see whether it might be a source of error in blood counts.

\section{Methods}

The Bürker counting chambers used were by several different manufacturers, but all had some variety of Neubauer ruling. The cover-slips were from 0.4 to $0.5 \mathrm{~mm}$. thick, and their position on the chambers was fixed by reference to permanent marks.

Blood from a finger-prick was diluted $1 / 10$ in a leucocyte pipette with 2 per cent aqueous acetic acid coloured with $50 \mathrm{mg}$. of crystal violet per $100 \mathrm{ml}$. The contents of the pipette were mixed by vigorous shaking for two and a half minutes, half the contents were rejected, and the counting chamber was filled with care to avoid bubbles and over-filling. The chamber stood on a perfectly flat surface until the leucocytes had settled.

Areas of 0.1 sq. $\mathrm{mm}$. on the counting chamber were defined by means of an eye-piece graticule and a $\frac{1}{6}$-inch objective, and the mechanical-stage vernier was used to set the fields of observation in rows $1 \mathrm{~mm}$. apart across the length of the chamber. In each row the cells were counted in nine fields with their centres $0.5 \mathrm{~mm}$. apart. In this way the whole filled area of the counting chamber was covered by a grid of observations with its boundaries $1 \mathrm{~mm}$. from the edges of the cover-slip and the troughs.

The numbers of leucocytes observed in the grid of areas was entered into a table of equidistant columns along the length of the chamber, and of equidistant rows running across the chamber. The totals for the nine columns over a large series of separate counts did not differ significantly, that is, the side-to-side variation in the leucocyte distribution did not differ from expectation. It was, therefore, possible to measure lengthwise variation in the leucocyte distribution simply by reference to the "row" totals, which were large enough to prevent the Poisson distribution from interfering with the analysis of variance.

With each chamber and length of cover-slip the counts were repeated until 500 to 800 cells had been counted in each position along the length of the chamber. The "row" totals in each count formed the basis of the statistical analysis. In all, some 150,000 leucocytes were counted.

\section{Single-cell Counting Chambers}

A series of leucocyte counts was made on singlecell counting chambers fitted with cover-slips $16 \mathrm{~mm}$. long in the longitudinal axis of the chamber. In 


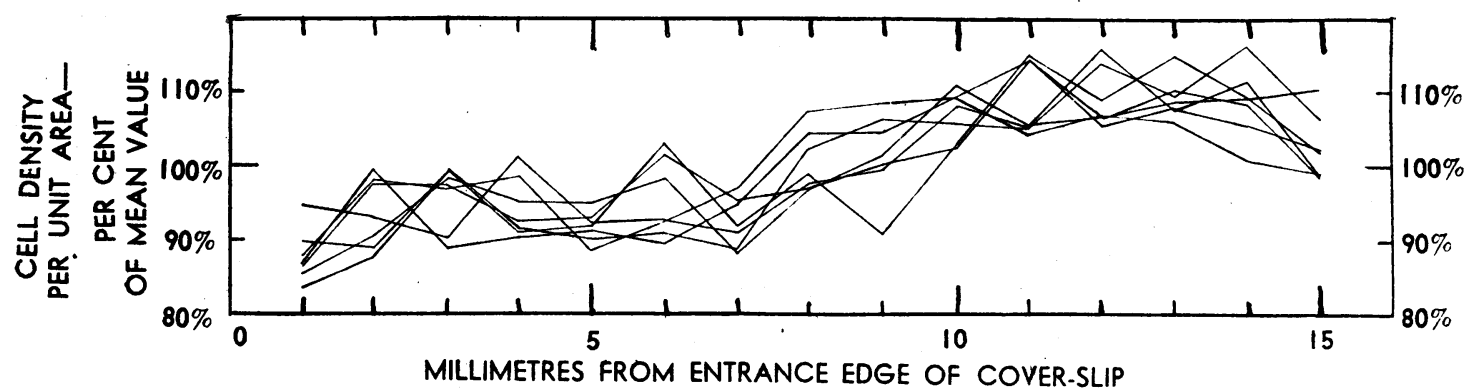

FIG. 1.-The leucocyte distribution on seven single-cell counting chambers. About ten counts were done on each chamber.

Fig. 1 each "curve" represents the total of nine or ten separate counts on seven counting chambers, each with its own cover-slip. Considerable random variation is to be expected in cell counts of the order of 500 , but in spite of this a very definite and constant trend in the leucocyte distribution is evident. The statistical analysis of these figures is summarized in the Table as an example of the methods used throughout the investigation.

\section{TABLE}

THE ANALYSIS OF VARIANCE OF THE LEUCOCYTE TOTAL IN FIFTEEN POSITIONS ON THE COUNTING CHAMBER IN SIXTY-NINE BLOOD COUNTS

\begin{tabular}{|c|c|c|c|c|}
\hline & $\begin{array}{l}\text { Degrees } \\
\text { of } \\
\text { freedom }\end{array}$ & $\begin{array}{l}\text { Sum of } \\
\text { squares }\end{array}$ & $\begin{array}{l}\text { Mean } \\
\text { square }\end{array}$ & $\begin{array}{l}\text { Vari- } \\
\text { ance } \\
\text { ratio }\end{array}$ \\
\hline $\begin{array}{l}\text { Between bloods } \\
\text { Between places } \\
\text { Residue }\end{array}$ & $\begin{array}{r}68 \\
14 \\
952\end{array}$ & $\begin{array}{r}226,164.87 \\
18,424.61 \\
65,893.69\end{array}$ & $\begin{array}{r}3,325.95 \\
1,316.04 \\
69.216\end{array}$ & $\begin{array}{l}48.0^{* * * *} \\
19.0^{* * *}\end{array}$ \\
\hline Total. & 1,034 & $310,483.17$ & & \\
\hline
\end{tabular}

\begin{tabular}{|c|c|c|c|c|}
\hline Between places & 14 & $18,424.61$ & $1,316.04$ & $19.0 * * *$ \\
\hline $\begin{array}{l}\text { Linear }\left(\xi_{1}\right) \\
\quad \text { Remainder }\end{array}$ & $\begin{array}{r}1 \\
13\end{array}$ & $\begin{array}{r}13,723.40 \\
4,701.21\end{array}$ & 361.63 & $5.22 * * *$ \\
\hline $\begin{array}{c}\text { Quadratic }\left(\xi_{2}\right) \\
\text { Remainder }\end{array}$ & $\begin{array}{r}1 \\
12\end{array}$ & $\begin{array}{r}273.23 \\
4,427.98\end{array}$ & 369.00 & $5.33^{* * *}$ \\
\hline $\begin{array}{l}\text { Cubic }\left(\xi_{3}\right) \\
\text { Remainder }\end{array}$ & $\begin{array}{r}1 \\
11\end{array}$ & $\begin{array}{l}2,049.92 \\
2,378.06\end{array}$ & 216.19 & $3.13^{* * *}$ \\
\hline $\begin{array}{c}\text { Quartic }\left(\xi_{4}\right) \\
\text { Remainder }\end{array}$ & $\begin{array}{r}1 \\
10\end{array}$ & $\begin{array}{l}1,344.89 \\
1,033.17\end{array}$ & 103.32 & 1.49 \\
\hline $\begin{array}{c}\text { Quintic }\left(\xi_{5}\right) \\
\text { Remainder }\end{array}$ & $\begin{array}{l}1 \\
9\end{array}$ & $\begin{array}{l}423.30 \\
609.87\end{array}$ & 67.76 & \\
\hline
\end{tabular}

The analysis of variance is first divided between "bloods"- due to the different leucocyte contents of the 69 specimens of blood used-and between "places"-representing the varying density of leucocyte distribution along the length of the counting chamber. The residual variance is a measure of experimental error, and is made up mostly of the component due to random sampling from a basically Poisson distribution. (The mean "row" total was 57.939.)

The significance of the difference between places is beyond question, so we next determine whether the variation in leucocyte density along the counting chamber can be represented by a straight line, or whether a more complex curve is necessary. This point is tested by fitting successive orthogonal polynomials (Fisher and Yates, 1943). The second half of the analysis in the Table shows how the calculation of each successive term removes a part of the sum of squares with a degree of freedom, until the remaining variance is not significantly greater than the residual variance. An alternative comparison is between the mean square from each term of the polynomials and the corresponding remainder mean square. This method gives the following values for the variance ratios:

$\xi_{1} 38.0 * * * \xi_{2}$ subnormal $\xi_{3} 9.48 * \xi_{4} 13.01 * * \xi_{5} 6.25 *$.

All the terms except the quadratic are significant.

The conclusion is that the variation in leucocyte distribution along the counting chamber cannot be represented by a straight line, but demands a quartic polynomial. This is a curve with a maximum towards either end of the cover-slip, as is shown in the subsequent figures.

It has often been surmised that the lines of the ruled area disturb the cell distribution on the counting chamber, but no significant effect was demonstrated in these observations. Fig. 2 contrasts the leucocyte distribution when the ruled area was under the centre of the cover-slip and when it was near to either end. The difference between the three curves is no greater than would be expected from random variation. 
The total length of counting-chamber under the cover-slip has a considerable effect on the shape of the leucocyte distribution curve (Fig. 3), but all the curves have one important common propertythat the leucocyte density reaches its mean value half-way along the cover-slip. If; therefore, the ruled area does not lie exactly under the centre of the coverslip, the count will tend to be either too high or too low. The curves further show that the longer the cover-slip the less is the error from the ruled area not being

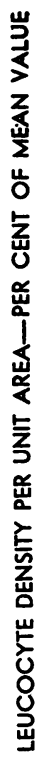
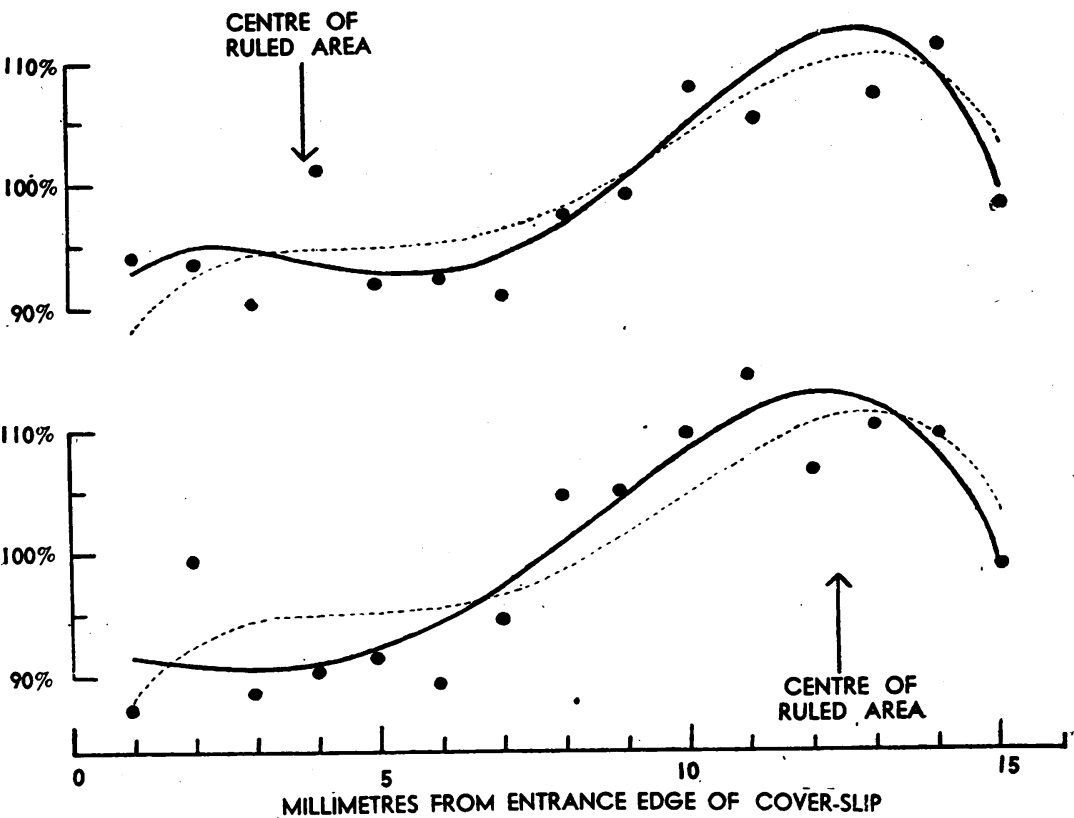

Fig. 2.-The leucocyte distribution on single-cell counting chambers with the ruled area under the centre of the cover-slip (broken line) or towards either end (continuous lines). The curves are the best-fitting quartics; the dots show the observed values relating to the continuous lines.

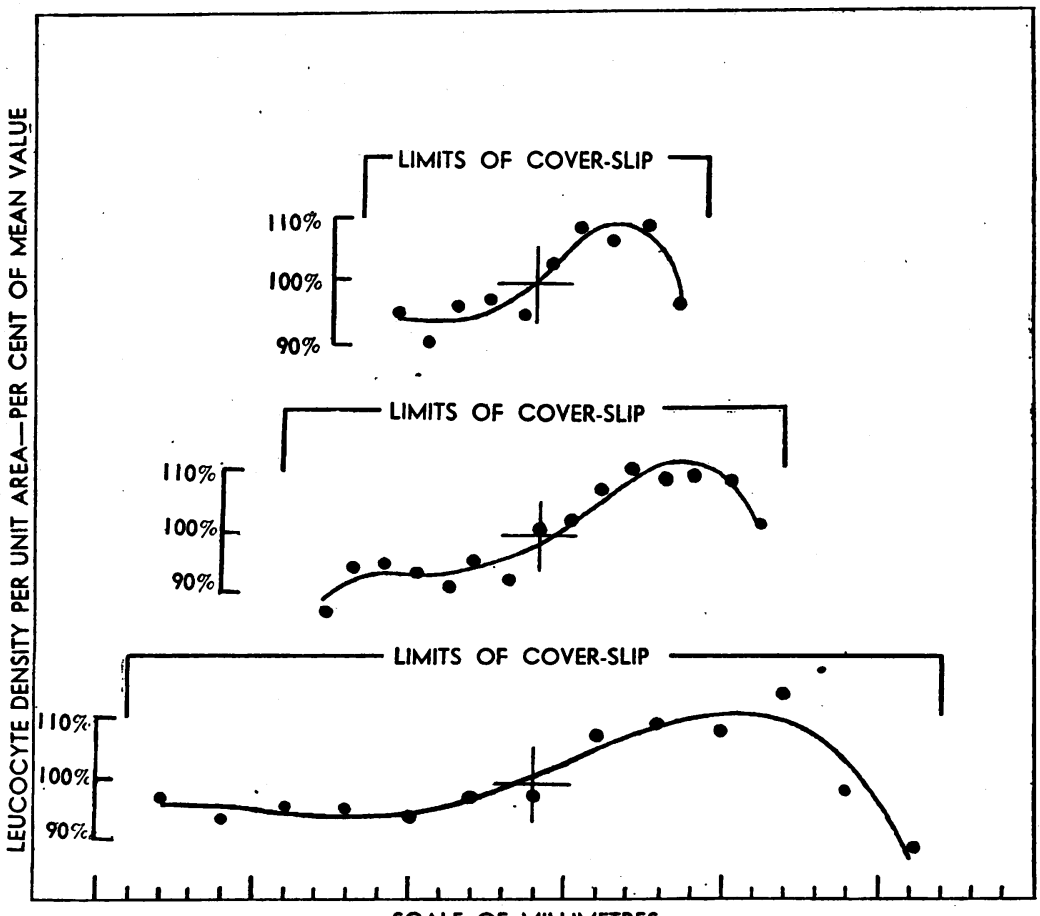

SCALE OF MILLIMETRES

Fig. 3.-The leucocyte distribution on single-cell counting chambers with cover-slip of different lengths. The dots mark the observed values; the curves are the bestfitting quartics. The crosses mark the centre of the cover-slip and the mean value. central. If the ruled area lies $1 \mathrm{~mm}$. away from the centre of the cover-slip, the error introduced is 4 per cent if the cover-slip is $11 \mathrm{~mm}$. long, 3 per cent if it is $16 \mathrm{~mm}$. long, and 2 per cent if it is $26 \mathrm{~mm}$. long.

\section{Double-cell \\ Counting Chambers}

The leucocyte-distribution on double-cell counting chambers (with a central trough and two ruled areas) varies in a very similar fashion (Fig. 4). Again the rule holds that the leucocyte density reaches its mean half-way along the coverslip. The cover-slip should therefore be so placed that its edge and the edge of the central trough are equidistant from the centre of the ruled area. This is easily ensured by a suitable 


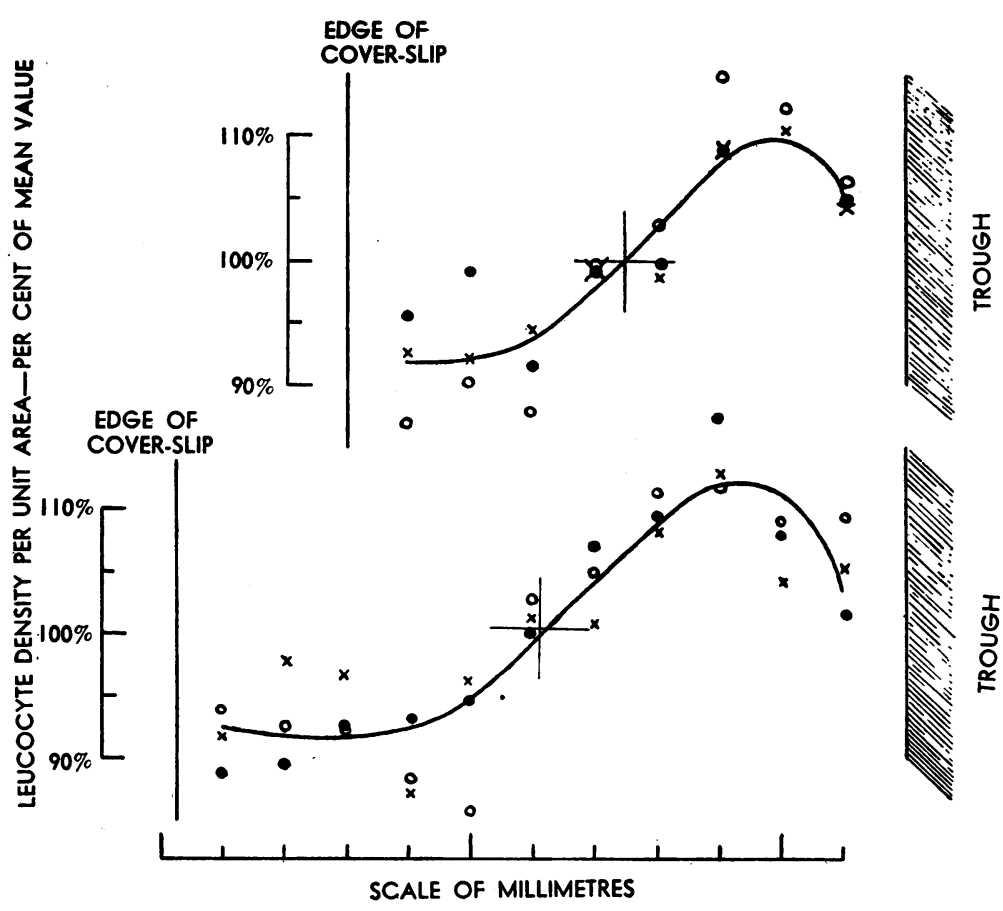

Fig. 4.-The leucocyte distribution on one side of double-cell counting chambers. The observed values from twelve counts on each of three are the best-fitting quartics to the whole series. The crosses mark the mean value and the centre of the filled area of the cell. counting-chambers with two cover-slips lengths are marked; the curves

\section{Reasons for the Effect}

It is very unlikely that this variation in the leucocyte density on the counting chamber is due to bending of the standard cover-slips under capillary tension. A bending of this sort should produce a symmetrical distortion of the leucocyte distribution, rather than the asymmetrical distortion demonstrated, and different cover-slips would not produce such very similar effects.

The possibility that the uneven leucocyte distribution arose in the capillary stem of the pipette was also excluded. A 1/10 dilution of blood in leucocyte-counting fluid was made in small tubes containing glass beads, and after thorough mixing a drop of the fluid was transferred to a counting chamber with a platinum loop. It is not possible by this technique to fill the counting chamber with real accuracy, but the leucocyte distribution on the counting chamber

mark when only one side of the counting chamber is in use, but if both sides are used simultaneously the cover-slip itself must be of the proper size.

The ruled area should be as far as is reasonably practicable from the central trough $(5 \mathrm{~mm}$. is a suitable distance), for the longer the area under the cover-slip the less is the slope of the leucocyte-distribution curve. Thus if the area covered is $9 \mathrm{~mm}$. long, a displacement of 1 $\mathrm{mm}$. of the cover-slip from "true centre" will lead to an error of 4.5 per cent, whilst if the area is $12 \mathrm{~mm}$. long a displacement of $1 \mathrm{~mm}$. will lead to an error of only 2 per cent.

Much greater errors may be introduced if no attempt is made to position the cover-slip. Some counting chambers have the centre of the ruled area only $3 \mathrm{~mm}$. from the central trough; if $12 \mathrm{~mm}$. of the cell in such a chamber were filled the leucocyte count would be nearly 12 per cent too high. agreed reasonably well with that obtained by the ordinary method (Fig. 5).

The true explanation of the uneven leucocyte distribution on the counting chamber seems to be the drift of the leucocytes along the chamber. When

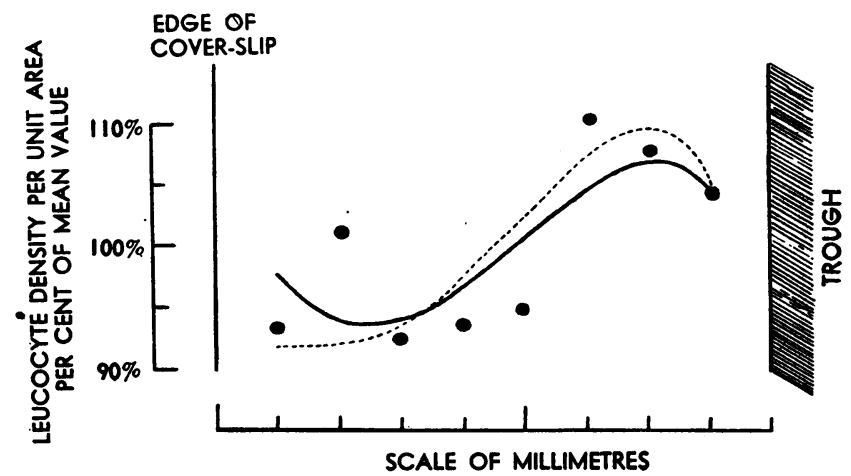

FIG. 5.-The leucocyte distribution on a counting chamber filled from a leucocyte pipette (broken line) and by the "tube and loop" technique (continuous line). The curves are the best-fitting quartics; the dots mark the observed values relating to the continuous line. 
the chamber is filled, the leucocytes, having a greater density than the diluting fluid, will continue to flow forward after the fluid has stopped. The higher above the surface of the counting chamber a cell is when filling is completed, the further along the chamber the cell will float before it settles. Thus the nearer end of the chamber will lose leucocytes which will concentrate towards the further end.

This initial impetus of the leucocytes must soon be lost, but observation shows that any floating leucocyte is usually moving along the longitudinal axis of the counting chamber. This movement, which is probably engendered by convection currents as the fluid dries, is most marked at the two ends of the cover-slip, and is in the direction of the closer edge. Thus the secondary leucocyte drift tends to remove leucocytes from the middle of the cover-slip and to deposit them towards either end, so that the leucocyte-distribution curve has the two maxima shown above.

Floating leucocytes very rarely show any appreciable lateral drift, so that in any narrow segment across the chamber the leucocyte distribution obeys the Poisson law.

\section{Discussion}

It is clear that considerable errors can be introduced into a leucocyte count if account is not taken of the variation in leucocyte density along the counting chamber. The count may be as much as 10 per cent too low if cells are counted in an area between the "entrance edge" of the cover-slip and the centre of the filled area, or 10 per cent too high if cells are counted beyond the centre. The true leucocyte count is obtained only if cells are counted in areas symmetrically disposed about the centre of the filled area.

The leucocyte distribution curve has a steep gradient in the middle third of the filled area, but the steepness decreases as the length of counting chamber filled increases. With a length of $9 \mathrm{~mm}$. the leucocyte density per unit area changed at the rate of 5 per cent per $\mathrm{mm}$. at the centre of the filled area, whereas with a length of $26 \mathrm{~mm}$. the rate of change was only 2 per cent per mm.

Thus the longer the area of counting chamber filled, the less will be the error from small inaccuracies in placing the cover-slip.

We should therefore make some new rules for blood-counts. With single-cell chambers the coverslip should cover as much as possible of the chamber, and should be so placed that the ruled area lies exactly under its centre. With double-cell chambers, since both sides will normally be used together, the cover-slip should be of such a length that both ruled areas lie midway between an edge of the cover-slip and the nearer edge of the central trough. The ruled area should be as far as possible from the central trough, so long as it can still be centred under the cover-slip. Finally, when the cover-slip has been properly placed it is still necessary to remember the steep change in leucocyte density across the ruled area, and to count squares symmetrically disposed about the centre.

It is probably not possible to use the leucocytedistribution curves obtained above to obtain a precise correction factor when the ruled area is not truly central. The central position of the mean value seems to be constant, but the shape of the curves must be influenced by many factors such as the viscosity of the diluting fluid and the rate of evaporation.

It seems, from a limited number of experiments, that the red-cell distribution on the counting chamber varies in a similar way to the leucocyte distribution. The slope of the curve is less, but the rule holds that the mean value is reached in the centre of the filled area.

\section{Summary}

1. The density of leucocytes per unit area on the counting chamber increases progressively from the point of entrance of the fluid along the length of the chamber.

2. The cell distribution in a narrow segment across the chamber obeys the Poisson law.

3. The curve of the leucocyte distribution along the chamber has two maxima, and statistically is adequately represented by a quartic polynomial.

4. The position of the ruled area does not affect the shape of the leucocyte-distribution curve.

5. The mean value for the leucocyte density per unit area is reached at the centre of the filled area of the chamber.

6. The rate of change in the leucocyte density is less the longer the filled area of the counting chamber.

7. The variation in the leucocyte distribution is not due to bending of the cover-slip, nor to any change in the cell distribution in the pipette before the chamber is filled. It appears to be due to the drift of the leucocytes caused by their initial forward impetus and subsequent convection currents.

8. Recommendations are made to counteract errors due to variation in the leucocyte distribution.

9. The distribution of red cells on the counting chamber follows similar laws to the distribution of leucocytes.

\section{REFERENCE}

Fisher, R. A., and Yates, F. (1943). "Statistical Tables for Biological, Agricultural, and Medical Research," 2nd ed. Oliver and Boyd. London. 